\section{A) Check for updates}

Cite this: Food Funct., 2020, 11, 2943

\title{
A lupine (Lupinus angustifolious L.) peptide prevents non-alcoholic fatty liver disease in high-fat-diet-induced obese mice $\uparrow$
}

\author{
Ana Lemus-Conejo, $t^{a, b}$ Elena Grao-Cruces, $t^{b}$ Rocio Toscano, ${ }^{a, b}$ \\ Lourdes M. Varela, ID c Carmen Claro, ' Justo Pedroche, ${ }^{a}$ Francisco Millan, ${ }^{a}$ \\ Maria C. Millan-Linares (D) *a,e and Sergio Montserrat-de la Paz iD b
}

\begin{abstract}
Bioactive peptides are related to the prevention and treatment of many diseases. GPETAFLR is an octapeptide that has been isolated from lupine (Lupinus angustifolius L.) and shows anti-inflammatory properties. The aim of this study was to evaluate the potential activity of GPETAFLR to prevent non-alcoholic fatty liver disease (NAFLD) in high-fat-diet (HFD)-induced obese mice. C57BL/6J mice were fed a standard diet or HFD. Two of the groups fed the HFD diet were treated with GPETAFLR in drinking water at $0.5 \mathrm{mg} \mathrm{kg}^{-1} \mathrm{day}^{-1}$ or $1 \mathrm{mg} \mathrm{kg}^{-1}$ day $^{-1}$. To determine the ability of GPETAFLR to improve the onset and progression of non-alcoholic fatty liver disease, histological studies, hepatic enzyme profiles, inflammatory cytokine and lipid metabolism-related genes and proteins were analysed. Our results suggested that HFD-induced inflammatory metabolic disorders were alleviated by treatment with GPETAFLR. In conclusion, dietary lupine consumption can repair HFD-induced hepatic damage possibly via modifications of liver's lipid signalling pathways.
\end{abstract}

Received 22nd January 2020

Accepted 25th March 2020

DOI: $10.1039 /$ dOfo00206b

rsc.li/food-function over, their growth procedure is cheap and simple. Therefore, peptides are an ideal target for obtaining bioactive compounds. The main sources of peptides are soy, eggs, milk, and fish. ${ }^{3}$ The main ways by which the bioactive peptides act on human health are as follows: decreased inflammation, lower blood pressure, anti-obesity, and prevention and improvement in the symptoms related to diabetes. ${ }^{4}$ In addition, the diseases that are on the rise in developed countries such as obesity, dyslipidemias, type II diabetes, metabolic syndrome, and nonalcoholic fatty liver disease (NAFLD) have pharmacological treatment that is not fully effective and also has adverse side effects. ${ }^{5}$ This is why many scientists are looking for substances of plant origin that can alleviate or prevent these diseases. ${ }^{6}$

Bioactive peptides contain a short sequence of amino acids with different biological activities. Initially, they are found in protein precursors in the organism of origin and they are generally not active. ${ }^{7,8}$ Peptides are obtained from plant proteins as a result of enzymatic hydrolysis during digestion via fermentation by micro-organisms or by in vitro chemicals or enzymatic hydrolysis processes. ${ }^{7}$

Lupinus angustifolius $\mathrm{L}$. is one of the targets for the research of such peptides because it has a high amount of proteins and low fat content. ${ }^{9,10}$ GPETAFLR is an octapeptide isolated from Lupinus angustifolius $\mathrm{L}$. with the sequence glycine-prolineglutamic acid-threonine-phenylalanine-leucine-arginine. This peptide features a three-dimensional secondary structure of 
(a)

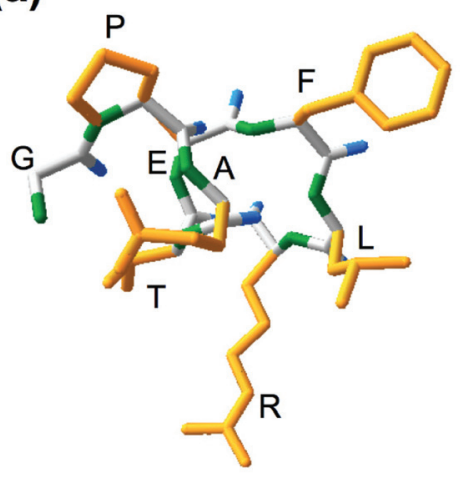

(b)

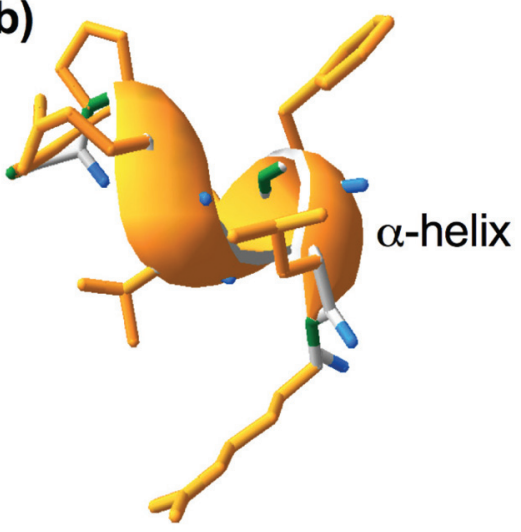

Fig. 1 Chemical (a) and secondary three-dimensional (b) structures of GPETAFLR peptide, an octapeptide isolated from Lupinus angustifolius L., for which the amino acid sequence is identified as Glycine (G), Proline (P), Glutamate (E), Threonine (T), Alanine (A), Phenylalanine (F), Leucine (L), and Arginine (R). Yellow color was used for the side chain, green color was used for the amino group, and blue color was used for the carboxyl group.

$\alpha$-helix (Fig. 1). Its immunomodulatory and anti-inflammatory capacities have been demonstrated. ${ }^{11}$ Its effects have been previously investigated in macrophage THP-1-line derivatives, ${ }^{11}$ osteoclasts derived from human primary monocytes, ${ }^{12}$ and primary human monocytes. ${ }^{13}$ Hence, it is an interesting compound to treat or prevent diseases characterized by inflammation.

Non-alcoholic fatty liver disease (NAFLD) is a health problem that affects a large percentage of the world's population with a global prevalence of $25 \%{ }^{14}$ The prevalence of this disease is very common in developed countries due to the fact that it typically occurs in people with obesity, type 2 diabetes, and metabolic syndrome among other pathologies related to lifestyle. ${ }^{15-18}$ NAFLD consists of the accumulation of fat in the liver tissue, which is derived from a high amount of free fatty acids (FFAs) and triglycerides (TGs) in the circulating blood. These levels may increase after higher caloric and fat intakes. For this reason, fatty liver disease is often associated with obesity and dyslipemias. ${ }^{15-18}$ The best models for the study of this disease are animal models of induced obesity; specifically, mice and rat models present pathogenesis more similar to humans. ${ }^{19}$ NAFLD has 4 phases: non-alcoholic fatty liver (NAFL), accumulation of fat in the liver; non-alcoholic steatohepatitis (NASH), liver fat accumulation with inflammation; fibrosis, accumulation of fat and inflammation resulting in tissue damage that drifts into fibrosis; and cirrhosis, most of the cells are replaced by fibrosis, thus considerably damaging the cellular hepatic function. This state leads to hepatic dysfunctionality, and the development of NAFLD may culminate in the development of liver cancer. ${ }^{18}$ Specifically, cirrhosis (last stage of NAFLD) is the major risk factor for developing hepatocellular carcinoma, the most common liver cancer. Hepatic steatosis is also related to the occurrence of hepatocellular carcinoma. ${ }^{20}$ Thus, NAFLD, even in its early stages, promotes the development of the most common type of liver cancer. Herein, the peptide GPETAFLR was used to investigate its role in the development of NAFLD in the hepatic tissues of mice with HFD-induced obesity.

\section{Materials and methods}

All animal protocols received appropriate institutional approval (Animal Care and Use Committee of the University of Seville) and were performed according to the official rules formulated in the Spanish law on the care and use of experimental animals (UE Directive of 2010: 2010/63/UE; RD 53/ 2013).

\section{Isolation, purification, and synthesis of GPETAFLR}

Seeds of sweet lupine (Lupinus angustifolius $\mathrm{L}$.) were a gift from Koipesol Semillas, S.A. (Seville, Spain). Alcalase $2.4 \mathrm{~L}$ was provided by Novozymes (Bagsvaerd, Denmark). Lupine protein isolate was obtained using a previously described method at the pilot plant scale (Plant Protein Unit, Instituto de la Grasa, Seville, Spain). ${ }^{21}$ The chemical composition of lupine protein isolate in dry matter was as follows: protein $86.83 \%$, dietary fiber $5.97 \%$, fat $5.08 \%$, ash $0.78 \%$, and carbohydrate $1.34 \%$. Lupine protein isolate was suspended in distilled water $(10 \%$ $\mathrm{w} / \mathrm{v}$ ), and hydrolysis with Alcalase was performed under the following conditions: $\mathrm{pH} 8,50^{\circ} \mathrm{C}, E / S=0.3 \mathrm{AU} \mathrm{g}^{-1}$ protein, and a hydrolysis time of $15 \mathrm{~min}$. The mixture was then heated at $85{ }^{\circ} \mathrm{C}$ for $15 \mathrm{~min}$ to inactivate the enzyme and centrifuged at $6500 \mathrm{~g}$ for $15 \mathrm{~min}$, and the supernatant constituted LPH. ${ }^{11}$ This fraction was purified by ultrafiltration and chromatographic techniques. ${ }^{22}$ The sequence of the purified peptide was identified through sequence analysis using nano-HPLC coupled with a Polaris Q ion-trap mass spectrometer (Mass Spectrometry Unit, Instituto de la Grasa, Seville, Spain). Finally, the peptide was synthesized by an Fmoc solid-phase method (Barcelona Scientific Park Foundation, Barcelona, Spain) at 95\% purity measured using HPLC-UV at $220 \mathrm{~nm}$.

\section{Animal diets and experimental design}

In order to keep the experimental number of mice as low as possible, forty male mice $\mathrm{C} 57 \mathrm{BL} / 6 \mathrm{~J}$ were used in the study. They were obtained from the Animal Production and Experimentation Centre at the University of Seville. The mice 
Table 1 Composition of standard chow and high-fat diets

\begin{tabular}{|c|c|c|c|}
\hline Macronutrients & & $\mathrm{kcal} \mathrm{kg}^{-1}$ & \%kcal \\
\hline \multicolumn{4}{|c|}{ Standard chow diet (amount per kg) } \\
\hline Protein & $205.9 \mathrm{~g}$ & 823.8 & 23.3 \\
\hline Fat & $55.1 \mathrm{~g}$ & 496.4 & 14 \\
\hline Carbohydrates & $554.2 \mathrm{~g}$ & 2216.8 & 62.7 \\
\hline Total & $815.2 \mathrm{~g}$ & 3537 & 100 \\
\hline \multicolumn{4}{|c|}{ High-fat diet (amount per kg) } \\
\hline Protein & $200.2 \mathrm{~g}$ & 800.9 & 1.6 \\
\hline Fat & $359.4 \mathrm{~g}$ & 3235.2 & 58.8 \\
\hline Carbohydrates & $374.1 \mathrm{~g}$ & 1496.3 & 26.7 \\
\hline Total & $933.7 \mathrm{~g}$ & 5505.4 & 100 \\
\hline
\end{tabular}

were divided into four groups ( $n=10$ per group), in which 3 of them were fed HFD and the last group was fed a standard chow diet (CD) and was used as a control group (210 SAFE, Augy, France). Mice were fed for 8 weeks. The HFD, which contained $60 \%$ energy as fat, was prepared by Panlab Laboratories (HF 260 SAFE) and presented as pellets to the animals (Table 1). Two of the experimental animal groups fed HFD were also treated with the synthesized GPETAFLR peptide, which was added into drinking water and administered at a dose of 0.5 or $1 \mathrm{mg} \mathrm{kg}^{-1} \mathrm{day}^{-1}$. Mice were anesthetized by an intraperitoneal injection of ketamine $\left(100 \mathrm{mg} \mathrm{kg}^{-1}\right)$ and diazepam $\left(5 \mathrm{mg} \mathrm{kg}^{-1}\right)$ and then euthanized by cervical dislocation. Hepatic tissues were immediately removed and then frozen at $-80{ }^{\circ} \mathrm{C}$ until processing. Homogenization was done with TRIsure (Bioline, Memphis, TN, USA).

\section{Dosage information}

Doses of 0.5 and $1 \mathrm{mg} \mathrm{kg}^{-1}$ day $^{-1}$ of the synthesized GPETAFLR peptide were established according to previous studies ${ }^{23-28}$ and the expected water consumption of the C57BL/6J strain. ${ }^{29}$ These selected doses for animals were comparable to human equivalent doses (HED) of 40 and $80 \mu \mathrm{g} \mathrm{kg}^{-1} .30$

\section{RNA isolation and real-time quantitative PCR analysis}

RNA from hepatic tissues was isolated to quantify gene expression by RT-qPCR. Total RNA was extracted by using TRIsure Reagent (Bioline). RNA quality was assessed by the $A_{260} / A_{280}$ ratio using a NanoDrop ND-1000 Spectrophotometer (Thermo Fisher Scientific, Madrid, Spain). Briefly, RNA (250 ng) was subjected to reverse transcription (iScript, Bio-Rad). An amount of $40 \mathrm{ng}$ of the resulting cDNA was used as a template for RT-qPCR amplifications. The mRNA levels for specific genes were determined in a CFX96 system (Bio-Rad). For each PCR reaction, a cDNA template was added to Brilliant SYBR green QPCR Supermix (Bio-Rad) containing the primer pairs for either gene or hypoxanthine phosphoribosyltransferase (HPRT) as a housekeeping gene. All amplification reactions were performed in triplicate and the average threshold cycle (Ct) numbers of the triplicates were used to calculate the relative mRNA expression of the candidate genes. The magnitude of the change in the mRNA expression for candidate genes was calculated by using the standard $2^{-(\Delta \Delta \mathrm{Ct})}$ method. All data were normalized to endogenous reference (HPRT) gene content and expressed as relative fold-change of control. The sequences of the designed oligonucleotides are shown in Table S1. $\dagger$

\section{Histological analysis}

Dissected liver sections were fixed overnight with $4 \%$ paraformaldehyde, cryoprotected with 15\%-30\% sucrose and embedded in Tissue-Tek OCT embedding medium (Sakura Finetek Europe, The Netherlands). Cryostat sections (8-10 microns) were rinsed with PBS and stained with a $0.3 \%$ solution of Oil Red $\mathrm{O}$ for 10 minutes at room temperature. After washing in PBS, the sections were counterstained with hematoxylin and eosin for 1 minute and washed with water. ${ }^{31}$ The percentage of the stained area was determined using Image J software.

\section{Biochemical analysis}

The levels of leptin in supernatants were measured by ELISA following the indications of the manufacturer (ThermoFisher). The adipokine concentrations were expressed in $\mathrm{ng}$ per $\mathrm{mL}$, as calculated from the calibration curves from a serial dilution of mice recombinant standards. In addition, the TG content in serum and liver tissues was determined by colorimetric enzyme assays (Bio-Science-Medical). The enzyme activities of liver enzymes, alkaline phosphatase (ALP), aspartate aminotransferase (AST), alanine aminotransferase (ALT) and lactate dehydrogenase (LDH) were measured using a commercial kit (Bio-Science-Medical) following the instructions. Absorbance was read using a microplate reader.

\section{Statistical analysis}

All values in the figures and text are expressed as the arithmetic mean \pm SD. Experiments were carried out in triplicate. Data were evaluated with GraphPad Prism Version 7.0 software (San Diego, CA, USA). The statistical significance of any difference in each parameter among the groups was evaluated by one-way analysis of variance (ANOVA) using Tukey's test for multiple comparison analyses. $P$ values $<0.05$ were considered statistically significant.

\section{Results}

\section{GPETAFLR decreases body and liver weight gain in HFD- induced obese mice}

After 8 weeks of diet, the animals showed body weight gain (Fig. 2(a)), and the increase in the body weight of the groups fed HFD was higher than that for the control group (Fig. 2(b)). Weight gain during the 8 weeks with HFD and GPETAFLR treatment at $1 \mathrm{mg} \mathrm{kg}^{-1} \mathrm{day}^{-1}$ was significantly lower (1.3-fold lower for HFD-GPETAFLR $\left(1 \mathrm{mg} \mathrm{kg}{ }^{-1}\right.$ day $\left.^{-1}\right)$ than HFD) than that for animals fed HFD not containing the peptide. Liver weight was also significantly higher in the obese control (animals fed only HFD) (1.3-fold lower for HFD-GPETAFLR (1 mg kg ${ }^{-1}$ day $\left.^{-1}\right)$ than HFD) with respect to that for the animals treated with GPETAFLR in drinking water (Fig. 2(c)). 
(a)

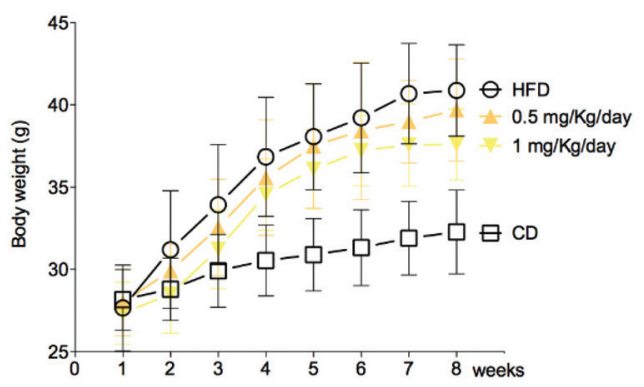

(c)

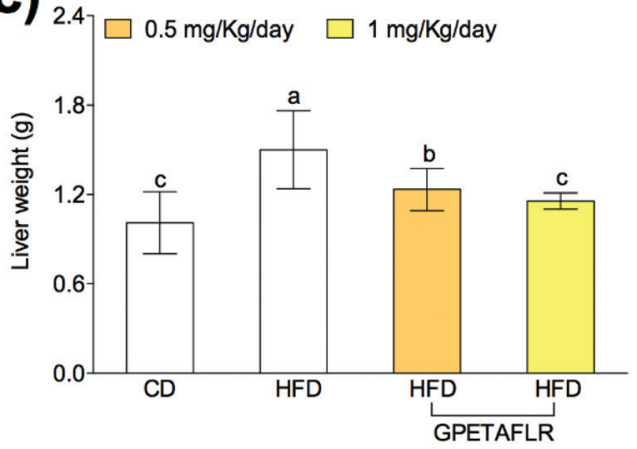

(b)

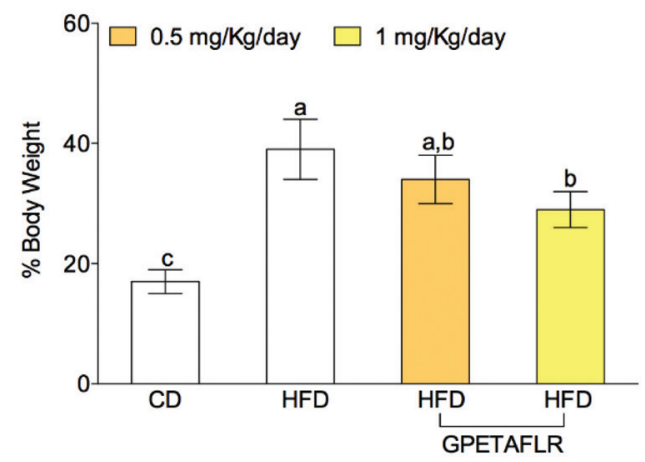

(d)

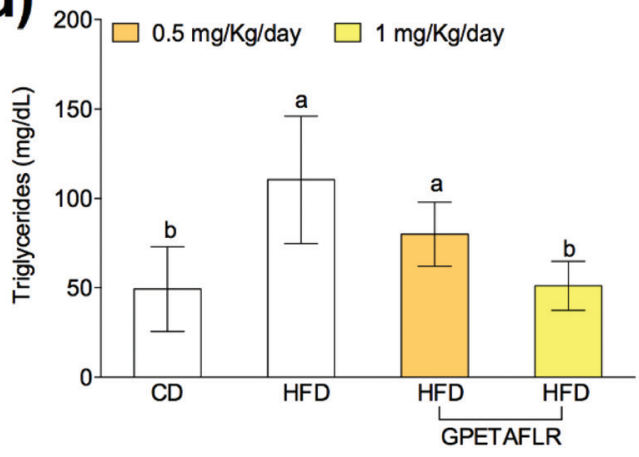

Fig. 2 Effect of GPETAFLR on the evolution of body weight (a), percentage of body weight gain (b), liver weight (c) and blood triglyceride levels (d) in mice fed a standard chow diet (CD), an HFD or an HFD + GPETAFLR at a dose of $0.5 \mathrm{mg} \mathrm{kg}^{-1}$ day $^{-1}$ and $1 \mathrm{mg} \mathrm{kg}^{-1}$ day ${ }^{-1}$ in drinking water. Values are presented as means \pm SD $(n=10)$ and those marked with different letters are significantly different $(P<0.05)$.

In line with the results described above, the level of TGs in the blood was significantly higher in the obese control group (2.1fold higher for HFD than HFD-GPETAFLR $\left(1 \mathrm{mg} \mathrm{kg}^{-1}\right.$ day $\left.^{-1}\right)$ ) with respect to that in the animals that, in addition to HFD, were treated with GPETAFLR in their drinking water (Fig. 2(d)). In this case, similar to that observed for liver weight, the effect of GPETAFLR was dose-dependent.

\section{GPETAFLR decreases hepatic leptin resistance in HFD-induced obese mice}

In obesity, the blood levels of leptin increase due to the lack of sensitivity between leptin and its receptor (OB-R), which is similar to that observed in insulin resistance. After 8 weeks of HFD, mice presented higher serum levels of leptin than the animals fed the standard diet (4.2-fold higher for HFD than CD) (Fig. 3(a)). The treatment with GPETAFLR significantly decreased these levels (2.7-fold lower for HFD-GPETAFLR ( $1 \mathrm{mg} \mathrm{kg}^{-1}$ day $^{-1}$ ) than HFD). Similarly, the OB-R mRNA levels were significantly higher in the animals fed HFD in contrast to that in the animals that did not receive GPETAFLR through drinking water (3.9-fold lower for HFD-GPETAFLR $\left(1 \mathrm{mg} \mathrm{kg} \mathrm{kg}^{-1}\right.$ day $^{-1}$ ) than HFD, Fig. 3(b)).

\section{GPETAFLR decreases hepatic steatosis in HFD-induced obese mice}

Fig. 4 shows the results of the histological study carried out with ORO and H\&E staining for the determination of the lipid content in hepatocytes. Fig. 4(a) shows the representative staining images of the histological slices of livers obtained from each experimental group. After 8 weeks of HFD, mice presented higher levels (3.2-fold higher for HFD than CD) of hepatic lipids than the animals fed a standard diet (Fig. 4(b)). The mice treated with GPETAFLR exhibited significant decrease in the hepatic steatosis induced by HFD (1.9-fold lower for HFD-GPETAFLR ( $1 \mathrm{mg} \mathrm{kg}^{-1} \mathrm{day}^{-1}$ ) than HFD).

\section{GPETAFLR modulates hepatic lipid metabolism-related genes} in HFD-induced obese mice

After 8 weeks of HFD, the levels of TGs in liver tissues were higher compared to that for CD (5.2-fold higher for HFD than CD, Fig. 5(a)). However, the TG levels were lower in the animals that were fed HFD and received GPETAFLR treatment (2.7-fold lower for HFD-GPETAFLR $\left(1 \mathrm{mg} \mathrm{kg}^{-1}\right.$ day $\left.^{-1}\right)$ than HFD). Significantly, GPETAFLR at $1 \mathrm{mg} \mathrm{kg}^{-1}$ day $^{-1}$ restored the values of $\mathrm{CD}$. In line with these results, the expression of the fatty acid synthase (FAS) enzyme (Fig. 5(b)) and peroxisome proliferator-activated receptor $\alpha$ (PPAR $\alpha)$ were determined (Fig. 5(c)). The FAS mRNA levels in the animals fed HFD were significantly higher than those in the animals fed CD (33.6-fold higher for HFD than CD) or treated with GPETAFLR (18.6-fold higher for HFD than CD). In addition, the transcriptional activity of PPAR $\alpha$ increased in the groups that received the octapeptide (6.6-fold higher for HFD-GPETAFLR 
(a)

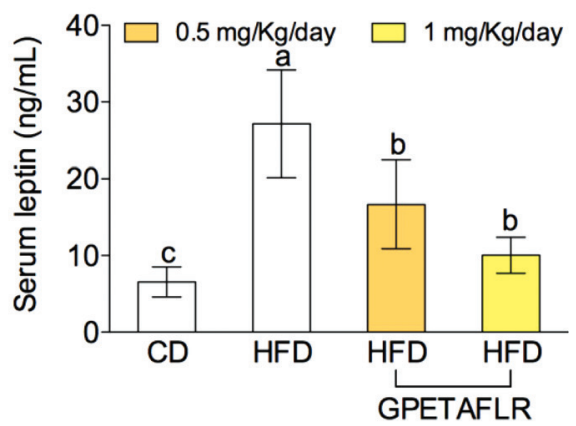

(b)

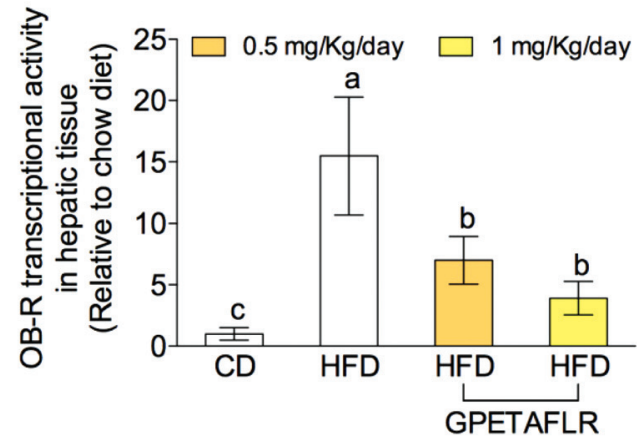

Fig. 3 Effect of GPETAFLR on leptin resistance. Serum leptin levels (a) and gene expression in leptin receptor hepatic tissue (OB-R) (b) in mice fed a standard chow diet (CD), an HFD or an HFD + GPETAFLR at a dose of $0.5 \mathrm{mg} \mathrm{kg}^{-1}$ day $^{-1}$ and $1 \mathrm{mg} \mathrm{kg}^{-1}$ day $^{-1}$ in drinking water. Values are presented as means $\pm \operatorname{SD}(n=10)$ and those marked with different letters are significantly different $(P<0.05)$.

(a)
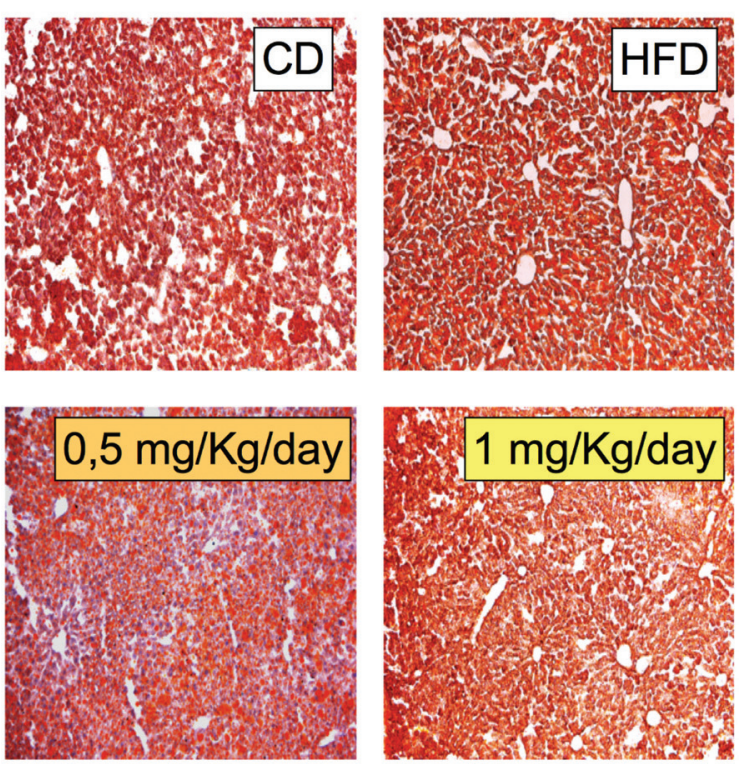

(b)

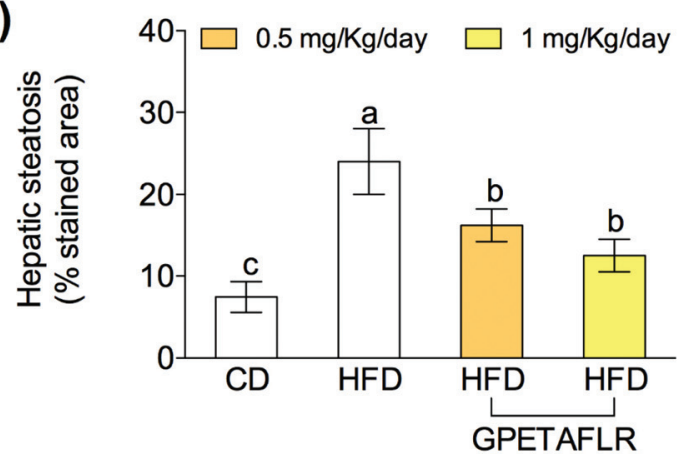

Fig. 4 Effect of GPETAFLR on hepatic steatosis. Representative images $(10 x)$ of stained histological slices with Oil Red O (ORO) and hematoxylin-eosin (H\&E) (a) and quantification of the stained area with ORO from each experimental group (b) in mice fed a standard chow diet (CD), an HFD or an HFD + GPETAFLR at a dose of $0.5 \mathrm{mg} \mathrm{kg}^{-1}$ day $^{-1}$ and $1 \mathrm{mg} \mathrm{kg}^{-1}$ day $^{-1}$ in drinking water. Values are presented as means \pm SD $(n=10)$ and those marked with different letters are significantly different $(P<0.05)$.
( $1 \mathrm{mg} \mathrm{kg}^{-1}$ day $^{-1}$ ) than HFD). Finally, the mRNA levels of mitochondrial decoupling protein 1 (UCP1) were determined (Fig. 5(d)). The treatment with GPETAFLR in drinking water significantly increased the hepatic transcriptional activity of UCP1 in comparison to those groups that did not receive the peptide (4.9-fold higher for HFD-GPETAFLR ( $1 \mathrm{mg} \mathrm{kg}^{-1} \mathrm{day}^{-1}$ ) than HFD).

GPETAFLR decreases hepatic inflammation in HFD-induced obese mice

After 8 weeks of HFD, the gene expressions of proinflammatory cytokines on hepatic tissues such as tumor necrosis factor $\alpha$ (TNF- $\alpha$ ) (Fig. 6(a)), interleukin $1 \beta$ (IL-1 $\beta$ ) (Fig. 6(b)), and interleukin 6 (IL-6) (Fig. 6(c)) were significantly higher in the animals fed exclusively with HFD. In both doses, GPETAFLR significantly decreased the mRNA levels of the pro-inflammatory cytokines. The gene expression of the anti-inflammatory cytokine interleukin 10 (IL-10) significantly increased in the mice that received GPETAFLR in drinking water compared to that in the groups that did not receive the peptide (5.1-fold higher for HFD-GPETAFLR ( $1 \mathrm{mg} \mathrm{kg} \mathrm{kgy}^{-1}$ ) than HFD, Fig. 6(d)).

\section{GPETAFLR decreases blood markers of liver damage in HFD-} induced obese mice

After 8 weeks of HFD, mice showed higher serum activity for AST (5.1-fold higher for HFD than HFD-GPETAFLR $\left(1 \mathrm{mg} \mathrm{kg}^{-1}\right.$ day $^{-1}$ ), Fig. 7(a)) and ALT (8.2-fold higher for HFD than HFD-GPETAFLR ( $1 \mathrm{mg} \mathrm{kg}{ }^{-1}$ day $^{-1}$ ), Fig. 7(b)) than those animals that received the GPETAFLR peptide in drinking water. GPETAFLR restored the values of transaminases to the levels in the animals fed CD. The activity of serum ALP was significantly higher in the obese control (1.4-fold higher for HFD than HFD-GPETAFLR ( $1 \mathrm{mg} \mathrm{kg}^{-1} \mathrm{day}^{-1}$ ), Fig. 7(c)). GPETAFLR at $1 \mathrm{mg} \mathrm{kg}^{-1}$ day $^{-1}$ restored the values of this marker to similar levels to the animals fed CD. On the other hand, the values for the serum activity of the enzyme LDH were higher in the obese control (2.8-fold higher for HFD than 
(a)

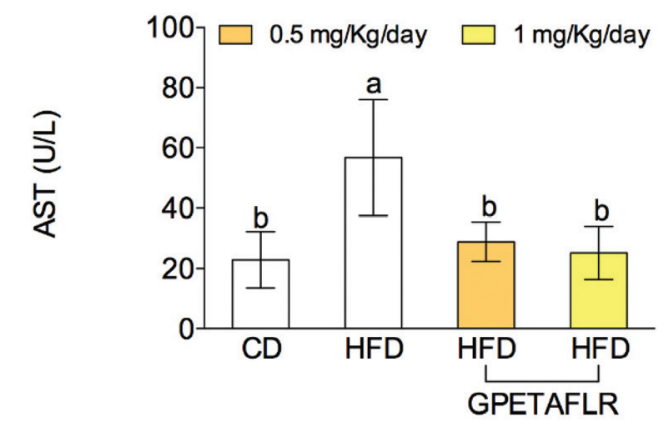

(c)

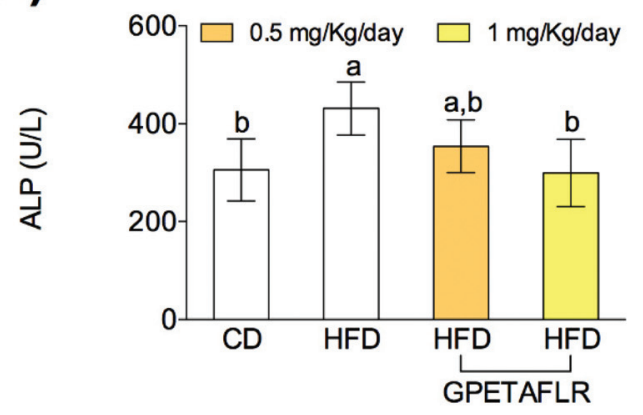

(b)

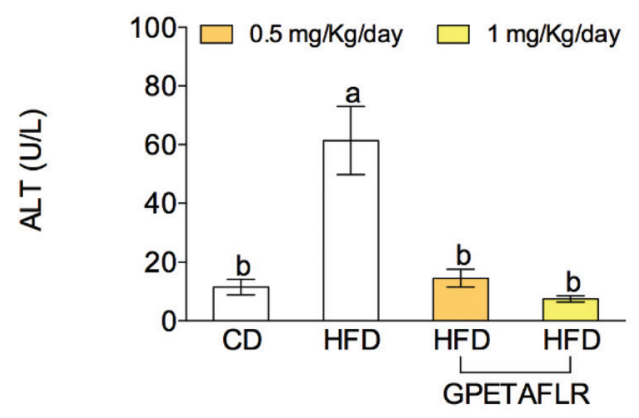

(d)

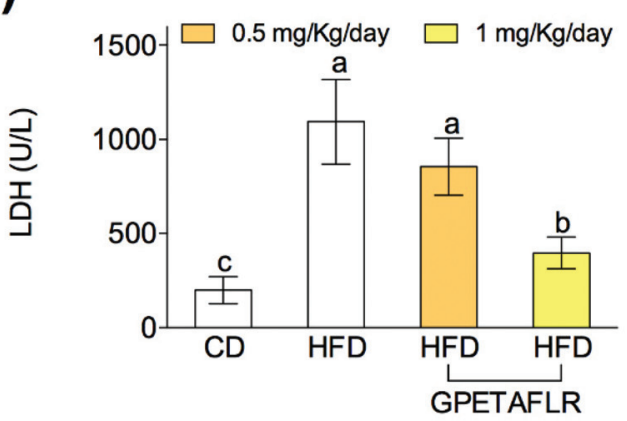

Fig. 7 Effect of GPETAFLR on serum liver damage markers such as aspartate aminotransferase (AST) (a), alanine aminotransferase (ALT) (b), alkaline phosphatase (ALP) (c) and lactate dehydrogenase (LDH) (d) in mice fed a standard chow diet (CD), an HFD or an HFD + GPETAFLR at a dose of $0.5 \mathrm{mg} \mathrm{kg}^{-1}$ day $^{-1}$ and $1 \mathrm{mg} \mathrm{kg}^{-1}$ day $^{-1}$ in drinking water. $C D$, chow diet, was used as a control group. Values are presented as means \pm SD $(n=10)$ and those marked with different letters are significantly different $(P<0.05)$.

HFD-GPETAFLR (1 mg kg $\left.{ }^{-1} \mathrm{day}^{-1}\right)$, Fig. 7(d)). GPETAFLR at $1 \mathrm{mg} \mathrm{kg}^{-1}$ day $^{-1}$ significantly decreased the values of this enzyme compared to that for the mice fed HFD without the GPETAFLR treatment.

\section{Discussion}

The use of bioactive peptides obtained from food is increasingly gaining importance because of their health benefits and use in preventing chronic diseases, whose incidences are increasing worldwide. ${ }^{4}$ Many chronic diseases are characterized by a marked inflammatory process. Therefore, GPETAFLR, a novel anti-inflammatory biopeptide obtained from Lupinus angustifolius L., can be a potent molecule for the prevention of these types of diseases. Its anti-inflammatory activity has been demonstrated. Specifically, both the peptide and the extracts of hydrolyzed lupin proteins have shown the ability to decrease the expression of pro-inflammatory cytokines and increase the expression of anti-inflammatory cytokines. ${ }^{11-13}$

The liver is the main metabolic organ of the body. NAFLD affects its functionality, endangering the homeostasis metabolic system. This disease is typically associated with obesity, ${ }^{15-18}$ where a substance that has the effect of reducing body weight and obesity rates will greatly alleviate the symptoms and development of NAFLD. The octapeptide GPETAFLR prevents the weight gain resulting from a diet rich in fat in contrast to other substances such as isoliquiritigenin with hepatoprotective properties that do not have the capacity to prevent weight gain. ${ }^{32}$ It can be said that GPETAFLR interferes by preventing the progression of the main cause of NAFLD: obesity.

On the other hand, the obtained data corroborated that the HFD-induced obese mice presented NAFLD pathophysiology similar to humans. The pathophysiology of this disease is characterized by increased body weight and liver weight, high levels of TGs in the blood, fat accumulation in adipose tissues, hepatic inflammation and elevated markers of liver damage. ${ }^{33}$ In our study, the obese control group showed a greater liver weight derived from a greater accumulation of fat in the liver. The accumulation may be due to high levels of TGs in the blood and the increase in the FAS gene expression. In addition, this group presented a pro-inflammatory state provoked by high levels of the expressions of pro-inflammatory cytokines IL-6, IL-1 $\beta$, and TNF- $\alpha$ since the Kupffer cells increase their expression in response to hepatic fat accumulation. ${ }^{34}$ Finally, it presented elevated markers of liver damage since the activities of transaminases, LDH, and ALP in serum were significantly higher. These values were also obtained in other similar studies on HFD-induced obese animals. ${ }^{19,32,35-37}$

All these parameters of the pathology were palliated with the treatment with GPETAFLR owing to the fact that liver weight 
and liver fat accumulation were lower in the animals treated with the octapeptide. The factors that can influence the minor accumulation of hepatic fat in these individuals are a decreased gene expression of FAS and an increased expression of the enzymes that increase energy metabolism, such as UCP1 and PPAR $\alpha$. In addition, there is less circulation of TGs in the blood and the availability for its accumulation in different tissues including the liver. GPETAFLR could mediate the accumulation of hepatic fat by influencing the signaling pathways involved in the regulation of the gene expression or the activity of lipid metabolism proteins, such as the kinase pathway activated by AMP (AMPK). AMPK regulates the activity and expression of many important proteins related to metabolism; one of them is mTOR, another metabolic regulator. AMPK decreases the accumulation of fat (down-regulating FAS, between other proteins) and other metabolites and also down-regulates mTOR, the protein that increases the accumulation of fat and also has effects on the gene and protein expressions. ${ }^{38}$ In previous studies, GPETAFLR has been demonstrated to present antiinflammatory activity that is also exhibited by hepatocytes. The octapeptide decreased pro-inflammatory cytokine levels and increased the levels of the anti-inflammatory cytokine IL-10. IL-10 did not show a decrease in expression in the obese control compared to that in the standard control, but its expression greatly increased in the groups treated with GPETAFLR. These data are related to previous studies on other cell lines and primary cultures. ${ }^{11-13}$ Pro-inflammatory cytokines present several actions related to metabolism; for example, TNF- $\alpha$ decreases the degradation of fats and increases their accumulation, and IL-6 inhibits lipolysis and increases fat deposition. ${ }^{35,39}$ For this reason, in addition to contributing to tissue damage from chronic inflammation, they contribute to the development of NAFLD by boosting fat accumulation in the liver. Chronic inflammation is primarily mediated by the nuclear factor $\kappa \mathrm{B}(\mathrm{NF}-\mathrm{\kappa B})$ pathway, which stimulates the production of cytokines such as TNF- $\alpha{ }^{40}$ For this reason, GPETAFLR may decrease inflammation by influencing the NF$\kappa \mathrm{B}$ pathway. The NF- $\kappa \mathrm{B}$ pathway increases the expression of proinflammatory cytokines; this pathway can be activated by the interaction of free fatty acids with TLR4, a membrane receptor expressed by Kupffer cells, which produces a pro-inflammatory state. ${ }^{34}$ The down-regulation of this pathway can be determined by the reduction in fat accumulation in the liver associated with the treatment with GPETAFLR.

Another parameter used as a marker of NAFLD pathogenesis in this study was the measurement of blood markers for liver damage, specifically transaminases, ALP, and LDH. The activity of these enzymes in serum was lower in both GPETAFLR treatments compared to that in the obese control group. This effect is probably due to the fact that the peptide decreases liver damage by reducing the accumulation of fat and inflammation (influenced by the lower accumulation of fat) and thus all the tissue damage associated with a chronic inflammatory process.

On the other hand, leptin is an adipokine produced by adipose tissues, and the levels of this hormone in the blood are indicative of the body's fat reserves because it is produced proportionally to the amount of adipose tissues. Therefore, a higher amount of leptin results in a higher amount of fat reserve. ${ }^{41}$ Leptin resistance is a characteristic of most obesityassociated diseases. This syndrome is characterized by a rise in serum leptin due to the increase in adipose tissues, but there is a lack of its signaling because the tissues with receptors show resistance. A proof that leptin resistance is occurring is a high value of leptin in serum and the gene expression of its receptor in the tissues that express it, such as that observed in the animals of the obese control group. The liver is one of the organs that can present receptors for leptin and signaling by this molecule increases the catabolic metabolism, increases the degradation of fatty acids, decreases the synthesis of fatty acids and affects glucose metabolism, specifically hypoglycemia. ${ }^{41,42}$ Leptin resistance in NAFLD can mediate an increase in the accumulation of hepatic fat in its direct form by a lack of signaling in the liver. In addition, leptin resistance may enhance the progression of NAFLD due to its role in intake and satiety. Leptin can cross the blood-brain barrier once inside the central nervous system (CNS), activate the production of anorexigenic peptides and inhibit the production of orexigenic peptides. This role translates into the inhibition of appetite and therefore into a decrease in caloric intake. ${ }^{41}$ Supplementation with GPETAFLR produced a decrease in obesity-associated leptin resistance. These effects may be due to the fact that GPETAFLR decreases body weight or GPETAFLR decreases resistance to the leptin and therefore, there is a decrease in body weight. It may also be considered that both effects are produced. Other plant bioactive substances have been shown to have effects by decreasing the resistance to leptin without significantly affecting the body weight. $^{32}$

\section{Conclusions}

To conclude, GPETAFLR decreased body weight gain, liver weight and fat accumulation in the liver as well as TG levels in the blood and leptin resistance associated with obesity. GPETAFLR showed anti-inflammatory properties at the hepatic level, decreasing the mRNA levels of pro-inflammatory cytokines such as TNF- $\alpha$, IL-6 and IL-10 and increasing the expression of the anti-inflammatory cytokine IL-10 in liver tissues. The octapeptide also reduced blood markers related to liver damage such as AST, ALT, ALP, and LDH. Taken together, our findings suggest that the use of GPETAFLR is a potential treatment as well as an important preventive therapy for NAFLD. Thus, the dietary supplementation with Lupinus angustifolius L. would also contribute to a reduction in this pathology.

\section{Conflicts of interest}

The authors declare no conflict of interest. 


\section{Acknowledgements}

The authors thank Cell Biology Unit at the Instituto de la Grasa for its assistance during the fulfilment of this study. SMP and LMV acknowledge financial support from "V and VI Own Research Plan”, respectively (University of Seville).

\section{References}

1 M. Malaguti, G. Dinelli, E. Leoncini, V. Bregola, S. Bosi, A. F. Cicero and S. Hrelia, Bioactive peptides in cereals and legumes: agronomical, biochemical and clinical aspects, Int. J. Mol. Sci., 2014, 15, 21120-21135.

2 A. Pihlanto, P. Mattila, S. Mäkinen and A. M. Pajari, Bioactivities of alternative protein sources and their potential health benefits, Food Funct., 2017, 8, 3443-3458.

3 K. Majumder, Y. Mine and J. Wu, The potential of food protein-derived anti-inflammatory peptides against various chronic inflammatory diseases, J. Sci. Food Agric., 2016, 96, 2303-2311.

4 S. Li, L. Liu, G. He and J. Wu, Function Molecular targets and mechanisms of bioactive peptides against metabolic syndromes, Food Funct., 2018, 9, 42-52.

5 M. F. Li and B. M. Cheung, Rise and fall of anti-obesity drugs, World J. Diabetes, 2011, 2, 19-23.

6 J. W. Yun, Possible anti-obesity therapeutics from nature A review, Phytochemistry, 2010, 71, 1625-1641.

7 E. Maestri, M. Marmiroli and N. Marmiroli, Bioactive peptides in plant-derived foodstuffs, J. Proteomics, 2016, 147, 140-155.

8 S. W. A. Himaya, D. H. Ngo, B. Ryu and S. K. Kim, An active peptide purified from gastrointestinal enzyme hydrolysate of Pacific cod skin gelatine attenuates angiotensin-1 converting enzyme (ACE) activity and cellular oxidative stress, Food Chem., 2012, 132, 1872-1882.

9 L. Day, Proteins from land plants - Potential resources for human nutrition and food security, Trends Food Sci. Technol., 2013, 32, 25-42.

10 N. Musco, M. I. Cutrignelli, S. Calabro, R. Tudisco, F. Infascelli, R. Grazioli, V. Lo Presti, F. Gresta and B. Chiofalo, Comparison of nutritional and antinutritional traits among different species (Lupinus albus L., Lupinus luteus L., Lupinus angustifolius L.) and varieties of lupin seeds, J. Anim. Physiol. Anim. Nutr., 2017, 101, 1227-1241.

11 M. C. Millan-Linares, F. Millan, J. Pedroche and M. M. Yust, GPETAFLR: A new anti-inflammatory peptide from Lupinus angustifolius L. protein hyrolysate, J. Funct. Foods, 2015, 18, 358-367.

12 M. C. Millan-Linares, A. Lemus-Conejo, M. M. Yust, J. Pedroche, A. Carrillo-Vico, F. Millan and S. Montserrat-de la Paz, GPETAFLR, a novel bioactive peptide from Lupinus angustifolius L. protein hydrolysate, reduces osteoclastogenesis, J. Funct. Foods, 2018, 47, 299-303.

13 S. Montserrat-de la Paz, A. Lemus-Conejo, R. Toscano, J. Pedroche, F. Millan and M. C. Millan-Linares,
GPETAFLR, an octapeptide isolated from Lupinus angustifolius L. protein hydrolysate, promotes the skewing to the M2 phenotype in human primary monocytes, Food Funct., 2019, 10, 3303-3311.

14 Z. M. Younossi, A. B. Koenig, B. Abdelatif, Y. Fazel, L. Henry and M. Wymer, Global epidemiology of non-alcoholic fatty liver disease. Meta-analytic assessment of prevalence, incidence, and outcomes, Hepatology, 2016, 64, 73-84.

15 U. J. Jung and M. S. Cho, Obesity and its metabolic complications: The role of adipokines and the relationship between obesity, inflammation, insulin resistance, dyslipidemia and nonalcoholic fatty liver disease, Int. J. Mol. Sci., 2014, 15, 6184-6223.

16 C. A. Rivera, Risk factors and mechanisms of non-alcoholic steatohepatitis, Pathophysiology, 2008, 15, 109-114.

17 L. Caballería, G. Pera, M. A. Auladell, P. Torán, L. Muñoz, D. Miranda, A. Aluma, J. D. Casas, C. Sanchez, D. Gil, J. Aubà, A. Tibau, S. Canut, J. Bernad and M. M. Aizpurua, Prevalence and factors associated with the presence of nonalcoholic fatty liver disease in an adult population in Spain, Eur. J. Gastroenterol. Hepatol., 2010, 22, 24-32.

18 R. Ullah, N. Rauf, G. Nabi, H. Ullah, Y. Shen, Y. Zhou and $\mathrm{J}$. Fu, Role of nutrition in the pathogenesis and prevention of non-alcoholic fatty liver disease: Recent updates, Int. J. Biol. Sci., 2019, 15, 265-276.

19 J. Carabelli, A. L. Burgueño, M. S. Roselli, T. F. Gianotti, N. R. Lago, C. J. Pirola and S. Sookoian, High fat dietinduced liver steatosis promotes an increase in liver mitochondrial biogenesis in response to hypoxia, J. Cell. Mol. Med., 2011, 15, 1329-1338.

20 C. Magini and J. F. Dufour, The story of HCC in NAFLD: from epidemiology, across pathogenesis, to prevention and treatment, Liver Int., 2016, 36, 317-324.

21 M. M. Yust, J. Pedroche, M. C. Millan-Linares, J. M. Alcaide-Hidalgo and F. Milan, Improvement of functional properties of chickpea proteins by hydrolysis with immobilized Alcalase, Food Chem., 2010, 122, 1212-1217.

22 M. C. Millan-Linares, B. Bermudez, M. M. Yust, F. Millan and J. Pedroche, Anti-inflammatory activity of lupine (Lupinus angustifolius L.) protein hydrolysates in THP-1derived macrophages, J. Funct. Foods, 2014, 8, 224-233.

23 Y. Liu, B. Luo, R. Shi, J. Wang, Z. Liu, W. Liu, S. Wang and Z. Zhang, Nonerythropoietic erythropoietin-derived peptide suppresses adipogenesis, inflammation, obesity and insulin resistance, Sci. Rep., 2015, 13, 15134.

24 B. Finan, B. Yang, N. Ottaway, D. L. Smiley, T. Ma, C. Clemmensen, J. Chabenne, L. Zhang, K. M. Habegger, K. Fischer, J. E. Campbell, D. Sandoval, R. J. Seeley, K. Bleicher, S. Uhles, W. Riboulet, J. Funk, C. Hertel, S. Belli, E. Sebokova, K. Conde-Knape, A. Konkar, D. J. Drucker, V. Gelfanov, P. T. Pfluger, T. D. Müller, D. Perez-Tilve, R. D. DiMarchi and M. H. Tschöp, A rationally designed monomeric peptide tritagonist corrects obesity and diabetes in rodents, Nat. Med., 2015, 21, 27-36.

25 D. Wu, Y. Gao, L. Chen, Y. Qi, Q. Kang, H. Wang, L. Zhu, Y. Ye and M. Zhai, Anti-tumor effects of a novel chimeric 
peptide on $\mathrm{S} 180$ and $\mathrm{H} 22$ xenografts bearing nude mice, Peptides, 2010, 31, 850-864.

26 T. Cichon, R. Smolarczyk, S. Matuszczak, M. Barczyk, M. Jarosz and S. Szala, D-K6L9 Peptide Combination with IL-12 Inhibits the Recurrence of Tumors in Mice, Arch. Immunol. Ther. Exp., 2014, 62, 341-351.

27 T. Nishimoto, L. Mlakar, T. Takihara and C. FeghaliBostwick, An endostatin-derived peptide orally exerts antifibrotic activity in a murine pulmonary fibrosis model, Int. Immunopharmacol., 2015, 28, 1102-1105.

28 D. H. Kim, S. C. Woods and R. J. Seeley, Peptide designed to elicit apoptosis in adipose tissue endothelium reduces food intake and body weight, Diabetes, 2010, 59, 907-915.

29 A. A. Bachmanov, D. R. Reed, G. K. Beauchamp and M. G. Tordoff, Food intake, water intake, and drink spout side preference of 28 mouse strains, Behav. Genet., 2002, 32, 435-443.

30 A. Nair, M. A. Morsy and S. Jacob, Dose translation between laboratory animals and human in preclinical and clinical phases of drug development, Drug Dev. Res., 2018, 79(8), 373-382.

31 E. Jurado-Ruiz, L. M. Varela, A. Luque, G. Berná, G. Cahuana, E. Martinez-Force, R. Gallego-Durán, B. Soria, B. de Roos, M. Romero Gómez and F. Martín, An extra virgin olive oil rich diet intervention ameliorates the nonalcoholic steatohepatitis induced by a high-fat "Westerntype" diet in mice, Mol. Nutr. Food Res., 2017, 61(3), DOI: 10.1002/mnfr.201600549.

32 Y. Lee, E. Y. Kwon and M. S. Choi, Dietary isoliquiritigenin at a low dose ameliorates insulin resistance and NAFLD in diet-induced obesity in C57BL/6J mice, Int. J. Mol. Sci., 2018, 19, 3281.

33 T. Wilkins, A. Tadkod, I. Hepburn and R. R. Schade, Nonalcoholic fatty liver disease: diagnosis and management, Am. Fam. Physician, 2013, 88, 35-42.
34 P. Li, K. He, J. Li, Z. Liu and J. Gong, The role of Kupffer cells in hepatic diseases, Mol. Immunol., 2017, 85, 222229.

35 Y. Meng, Y. Liu, N. Fang and Y. Guo, Hepatoprotective effects of Cassia semen ethanol extract on non-alcoholic fatty liver disease in experimental rat, Pharm. Biol., 2019, 57, 98-104.

36 M. H. Pan, G. Yang, S. Li, M. Y. Li, M. L. Tsai, J. C. Wu, V. Badmaev, C. T. Ho and C. S. Lai, Combination of citrus polymethoxyflavones, green tea polyphenols, and Lychee extracts suppresses obesity and hepatic steatosis in high-fat diet induced obese mice, Mol. Nutr. Food Res., 2017, 61(11), 1001104.

37 J. Vidé, B. Bonafos, G. Fouret, M. Benlebna, J. Poupon, B. Jover, F. Casas, N. Jouy, C. Feillet-Coudray, S. Gaillet and C. Coudray, Spirulina platensis and silicon-enriched spirulina equally improve glucose tolerance and decrease the enzymatic activity of hepatic NADPH oxidase in obesogenic diet-fed rats, Food Funct., 2018, 9, 6165-6178.

38 K. Burkewitz, Y. Zhang and W. B. Mair, AMPK at the nexus of energetics and aging, Cell Metab., 2014, 20, 10-25.

39 R. A. Memon, C. Grunfeld, A. H. Moser and K. R. Feingold, Tumor necrosis factor mediates the effects of endotoxin on cholesterol and triglyceride metabolism in mice, Endocrinology, 1993, 132, 2246-2253.

40 L. Catrysse and G. Van Loo, Inflammation and the metabolic syndrome: the tissue-specific functions of $\mathrm{NF}-\mathrm{kB}$, Trends Cell Biol., 2017, 27, 417-429.

41 T. A. Dardeno, S. H. Chou, H. S. Moon, J. P. Chamberland, C. G. Fiorenza and C. S. Mantzoros, Leptin in human physiology and therapeutics, Front. Neuroendocrinol., 2010, 31, 377-393.

42 A. M. D’Souza, U. H. Neumann, M. M. Glavas and T. J. Kieffer, The glucoregulatory actions of leptin, Mol. Metab., 2017, 6, 1052-1065. 